\title{
Evolution of Cornerstone: Creating a First-year Culture with a Multifaceted Approach
}

\section{Dr. Richard Whalen, Northeastern University}

Dr. Richard Whalen is a Teaching Professor at Northeastern University in Boston, MA and is Associate Director of First-year Engineering. The mission of the First-year Engineering team is to provide a reliable, wide-ranging, and constructive educational experience that endorses the student-centered and professionally-oriented mission of the University. He also teaches specialty courses in the Department of Mechanical and Industrial Engineering at Northeastern and has published and presented papers on approaches and techniques in engineering education. He has won multiple Outstanding Teaching Awards at Northeastern and numerous Best Paper and Best Presentation Awards with fellow First-year faculty coauthors at ASEE.

\section{Dr. Susan F. Freeman, Northeastern University}

Susan Freeman, is a member of Northeastern University's first-year engineering facutly, a group of teaching faculty expressly devoted to the first-year Engineering Program at Northeastern University. The focus of this team is on providing a consistent, comprehensive, and constructive educational experience that endorses the student-centered, professional and practice-oriented mission of Northeastern University.

\section{Ms. Jennifer Ocif Love, Northeastern University}

Jennifer Love is a full-time faculty member of Northeastern University's First Year Engineering Program in the College of Engineering. She is currently working toward a doctorate in education at Northeastern University with a focus on PreK-20 engineering education.

\section{Dr. Kathryn Schulte Grahame, Northeastern University}

Dr. Kathryn Schulte Grahame is an Associate Teaching Professor at Northeastern University. As part of her First-Year Faculty appointment she teaches freshman engineering courses as well as undergraduate civil engineering courses.

\section{Dr. Joshua L. Hertz, Northeastern University}

Dr. Hertz earned a B.S. in Ceramic Engineering from Alfred University in 1999 and then a Ph.D. in Materials Science and Engineering from the Massachusetts Institute of Technology in 2006. Following this, he worked at the National Institute of Standards and Technology as a National Research Council postdoctoral fellow. He joined the Department of Mechanical Engineering at the University of Delaware as an Assistant Professor in September 2008, leading a lab that researched the effects of composition and nanostructure on ionic conduction and surface exchange in ceramic materials. In 2014, he moved to Northeastern University to focus on teaching and developing curriculum for their First Year Engineering program. 


\section{Evolution of Cornerstone: Creating a First-Year Culture with a Multi-Faceted Approach}

$\underline{\text { Abstract }}$

This complete evidence-based practice paper presents an update of analysis and observations in a required first-year engineering curriculum at Northeastern University, which is a medium-sized, private, urban university. A curricula redesign resulted in a "cornerstone to capstone" approach with a pilot program rolled out to 2 sections of a first-year engineering course in the Fall of 2014. The goal of this cornerstone approach was to integrate design, programming, graphical communication, and engineering analysis previously taught in two separate first-year engineering courses by creating an 8 credit hour, 14 week course that focuses on real world, hands-on design projects. Now in its third year of continued refinement and analysis, the University is offering 5 sections of the 8 credit hour course (Full Cornerstone) and 20 sections of a version with 2 separate 4 credit hour courses (Split Cornerstone) that run over the fall and spring semester. Each section is populated with approximately 30 first-year students from a total first-year class size exceeding 700 students.

With two versions implemented over the past two years, there has been enough redesign to warrant more discussion. The course redesign has been driven by feedback and evidence, fundamentally following the design process we teach in the course. The data used to drive this redesign has come from four sources: 1) a survey of students in both the cornerstone and noncornerstone (original 2 course sequence) sections on many topics covering textbooks, pedagogy, concepts taught, self-efficacy in engineering, and more; 2) student feedback teams used in many sections of the course; 3) University-administered student evaluations given at the end of each semester; and 4) the first-year teaching team, which met frequently and worked each summer to improve course design and supporting materials.

This paper outlines the differences between the Full versus Split Cornerstone approaches and looks at the evolution of a first year culture and other positive effects created in instituting the new Cornerstone courses. The analysis includes how both the students and instructors are affected by each approach and the lessons learned along the way to make both Cornerstone approaches successful. A description of various projects and themes used to create the project based courses is included. Overall results show that the Cornerstone approach is successful and has created a positive student culture centered on the projects and the learning center where students work. Students have seen a positive improvement in their perspectives on engineering and self-efficacy in their abilities to become an engineer.

Introduction

Following a successful pilot, the first-year engineering program at Northeastern University decided to adopt the "cornerstone to capstone" curriculum design for all incoming first-year engineering students. The Cornerstone course specifically incorporates the integration of handson, project-based design projects with computer programming. Previously taught in two separate 
first-year engineering courses, the new Cornerstone course model provides a blend of programming and design in a way that shows our students that the two are intertwined.

Figure 1 below shows the conceptual framework for the cornerstone experience at the university. This model helps visualize how the goal of this program is to weave together three theme areas into an integrated design experience. From left to right, we see that the learning objectives include students being able to evaluate and interpret designs and programs, conceptualize and prototype them, and communicate them in diverse ways. This visualization of cornerstone allows the program instructors to organize learning objectives together, which can help in planning, teaching, and assessment purposes.

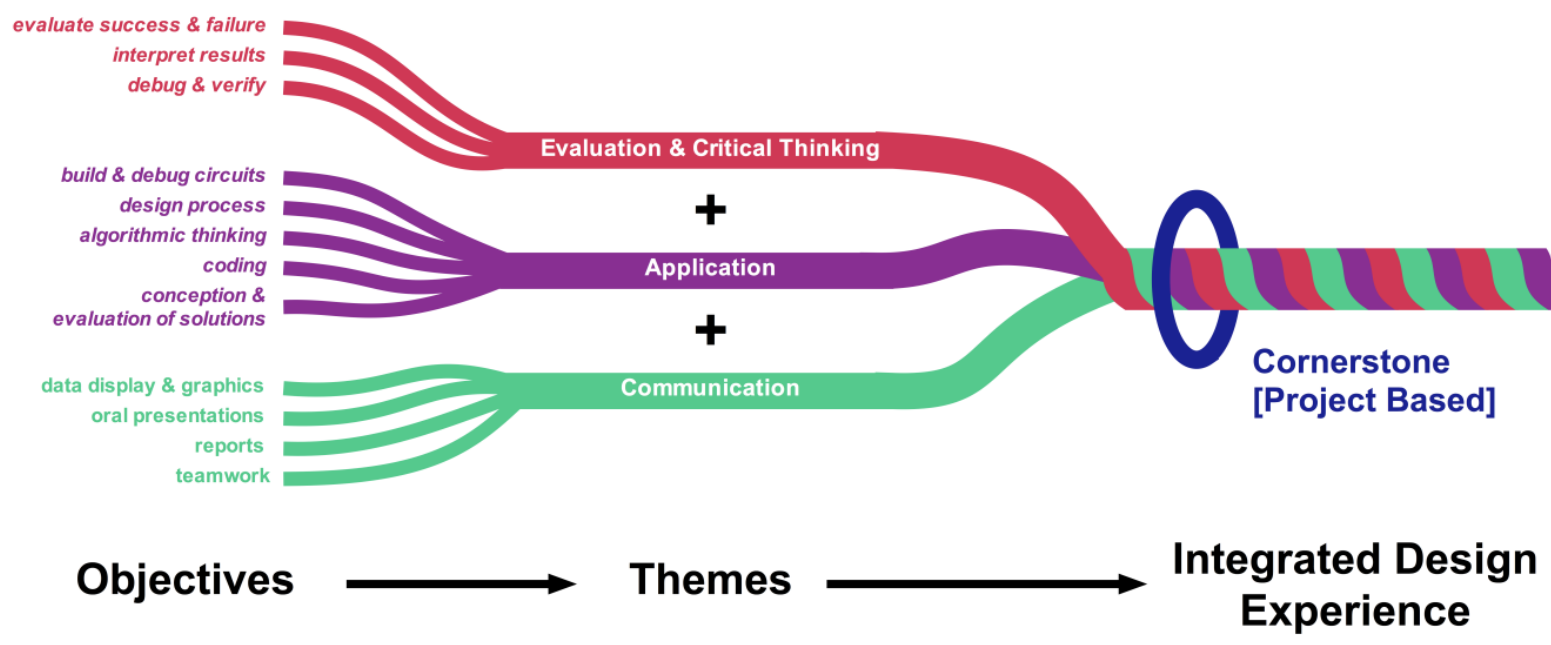

Figure 1 - Conceptual model of the cornerstone course [1].

Project-based cornerstone has, as one of its challenges, the ability to have incongruent learning of course content due to the nature of problem solving. By highlighting that engineering problem solving brings together groups of competencies in a networked fashion rather than in a linear fashion, we can help increase the quality of instruction for all students by showing them that this incongruence is acceptable. Specifically, the emphasis is that cornerstone is a lens by which engineering learning can come together to develop practical applications to solving problems. By representing cornerstone as a ring that brings together three theme areas, the conceptual framework focuses on the notion that it blends together seemingly separate aspects into a useful weave of skills in a problem solving context.

\section{Cornerstone Full and Split: 2 Approaches to Address the Changing Student Profiles}

The first-year is common for all engineering majors. The main reason a common first-year curriculum was instituted at Northeastern University is because of the many students who enter undecided (approximately 40\%). Accommodations are needed for these students so that they have an opportunity to explore all of the 7 engineering majors without penalty or delay. In addition to a large cohort of undecided students, the university is seeing an increased number of students coming in with college credit, either Advanced Placement (AP) or other. In 2014 when the original cornerstone pilot was completed, over $50 \%$ of entering students had some AP credit 
in Calculus, 20\% had Chemistry credit, 35\% have College Writing credit and 35\% have Physics credit. These students as well as current students with advanced credit face a limited course selection to complete their academic schedules in these early semesters since it is difficult to find courses that they can take in the first year that do not have prerequisites. This created the need to revise the curriculum to offer students the opportunity to accelerate their exploration of an engineering major. In order to accomplish this, students take the full cornerstone course (8 credits) in the fall semester. This option frees up one course in their spring semester to explore introductory courses in their major that would not usually be seen until the sophomore year. The students not looking to accelerate their introduction to a major in the spring are placed in the split cornerstone courses (8 credits over fall and spring semesters).

In both versions, the cornerstone courses were carefully designed to set up our first-year students to be successful in their 2nd year of engineering regardless of major selection. Therefore the courses include specific themes centered on a number of design-and-build projects with the following program objectives:

1. Provide students with the opportunity to experience engineering as an evolving, creative, and interdisciplinary career that impacts global society and daily life.

2. Provide students with the opportunity to develop process-driven problem solving skills that recognize multiple alternatives and apply critical thinking to identify an effective solution.

3. Provide students with the opportunity to integrate math \& science in an engineering context.

4. Create motivated \& passionate engineering students by challenging them with authentic engineering problems across multiple disciplines.

5. Instill in our students the professional, personal \& academic behaviors and common competencies needed to move to the next stage of their development.

The Cornerstone courses are currently offered in 5 sections of the 8 credit hour course (Full Cornerstone) and 20 sections of the 2 separate 4 credit hour course (Split Cornerstone). Each section is populated with approximately 30 first-year students from a total first-year class size exceeding 700 students. Following the design process taught in the course, there has been continual reevaluation and redesign of the course over the past two years. This redesign has been those iterative steps of identifying new problems with the delivery and implementation, doing more research, finding many creative options for improvement, working as a team to pilot and evaluate each, and repeating the process. The data used to drive this redesign has come from four sources. The first source is a survey of students in both the cornerstone and non-cornerstone (original 2 course sequence) sections on many topics covering textbooks, pedagogy, concepts taught, self-efficacy in engineering, and more. The second source was the student feedback teams used in many sections of the course. The third source is the University administered student evaluations given at the end of each semester. The fourth source is the first-year 
teaching team, which met frequently and worked each summer to improve course design and supporting materials.

\section{Literature Review}

In 2005, after a substantial review process that took several years and several committees of high ranking members from academia and industry, the National Academy of Engineering in its Educating The Engineer of 2020 report [2] recommended that engineering education establishments need to:

1. Pursue a student-centered approach to undergraduate engineering education.

2. Increase the value in engineering education research to better understand how students learn.

3. Develop new standards for faculty qualifications.

4. Help promote engineering and technological literacy among the public.

5. Introduce interdisciplinary learning at the undergraduate level.

Research has shown that effective engineering education stems from the fact that experiential, project-based, hands-on and interdisciplinary learning engages students and increases retention [3-7]. Key findings in the current literature on teaching show that real-world problems - when presented in an active and experiential learning environment - increase student interest, possess pedagogical effectiveness, and help to facilitate initial learning and transfer of that learning to other contexts [8]. Specifically, Dym et al. conducted their own literature review of projectbased learning and cornerstone courses to determine whether divergent and convergent thinking in the engineering design process could be used iteratively to develop better pedagogical approaches to engineering design and analysis [5]. They concluded that project-based learning increases retention of engineering students and that there is a clear need to increase the number of faculty who can teach engineering design and to create facilities and design studios that support project-based design courses.

An emerging teaching strategy that engages the student with his/her own learning involves the use of student feedback teams, also known as student management teams or quality circles [9], [10], [11], [12]. A student feedback team is a small group of volunteer students who meet regularly with the instructor to enhance their experiences and those of their classmates in the course. Throughout the semester, the team collects feedback from their peers through informal conversations and short in-class surveys, then processes it before sharing it with the instructor. The instructor then addresses the feedback with the whole class and implements any changes and improvements accordingly. Student feedback teams can be used in a variety of course disciplines and can increase motivation and engagement for both the students and the instructor. Students enrolled in courses with student feedback teams have reported feeling a greater sense of ownership of the course and a positive perception of the instructor's investment in their learning [10], [12]. The collaborative nature of a student feedback team can improve the overall course climate [9]. 
In 2017, ASEE published a report on the Maker movement in higher education based on surveys collected from 93 engineering deans, engineering technology deans, or department chairs and from 21 non-engineering academic maker community representatives (museum, library, K12, university, public sectors) [13]. They found that makerspaces that are integrated into curriculum and programs reported positive student outcomes. A cursory review of the engineering education literature reveals that makerspaces integrated into engineering curriculum create a positive culture for students [14], [15].

\section{$\underline{\text { Refining a Program and the Development of a First Year Engineering Culture }}$}

When setting out to develop the Cornerstone, our goal was to adjust to the changing profiles of our incoming students and to create better systems thinkers through the integration of our two first year courses. In analyzing the results of our first pilot, we saw that $100 \%$ of students described the new projects given in the Cornerstone course as integrating both programming and design [1]. We considered this an initial success, and initial feedback was positive, but we realized there were still many opportunities to improve our first-year program.

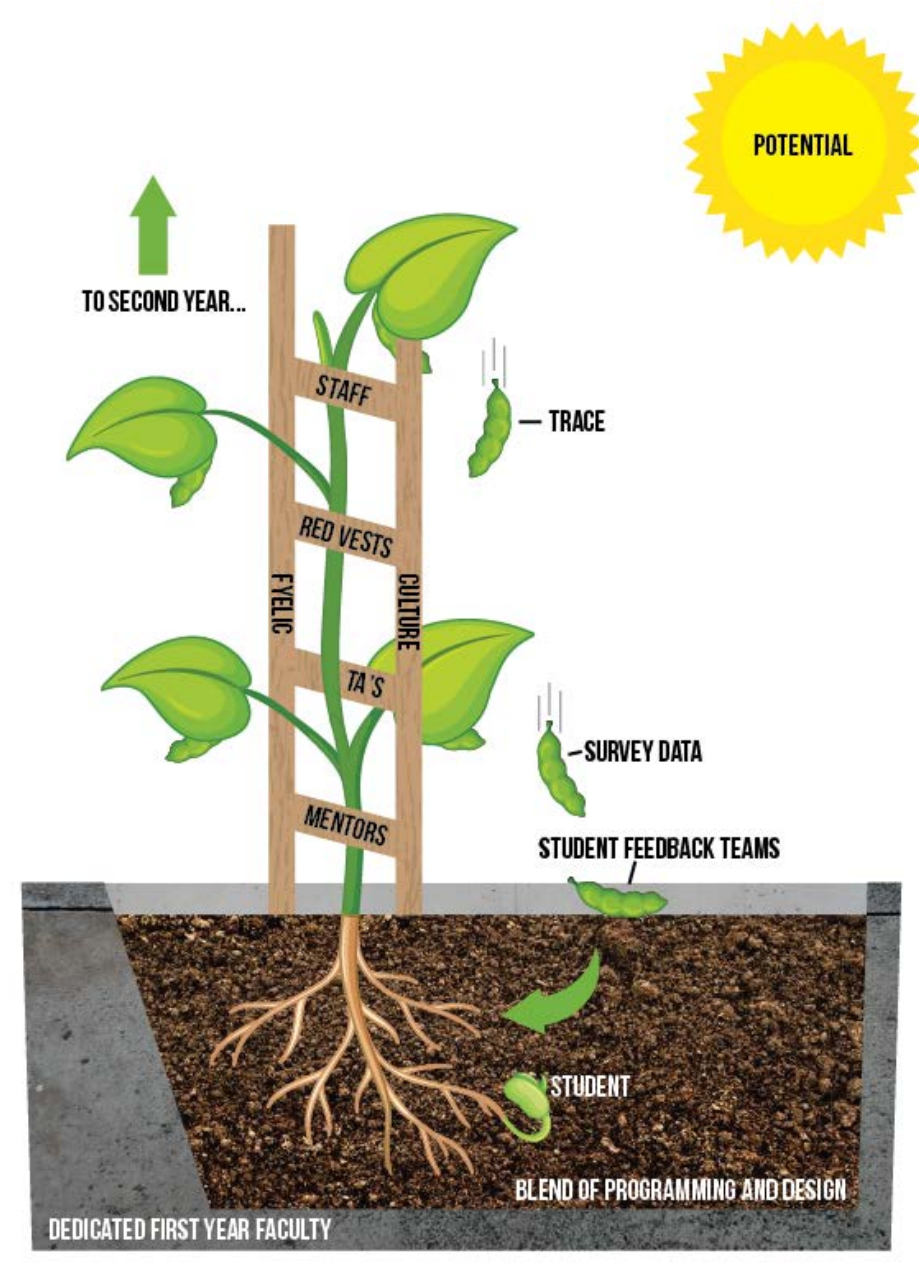

Figure 2 - Conceptual Model of Cornerstone Culture [1]. 
When examining the four methods of data previously mentioned (student surveys, student feedback teams, university course evaluations, and first-year faculty team collaboration), an unexpected - and highly welcome - secondary benefit became obvious. The first year program had evolved from two separate courses that were seemingly unlinked and unimportant, to a firstyear engineering culture that sustains a successful academic career. The culture most definitely revolves around the making of intensive class projects, but the complete first-year experience is much bigger than just a project. We recognize that the experience is something that was more organically grown through the efforts of many in the program, therefore, we will conceptualize

this creation of an experience through a theoretical framework that uses plant growth as shown in Figure 2.

If first-year students are thought to be seeds with the potential for growth then our previous model of teaching design and programming in separate courses was not the best medium for the students to take root. By emphasizing one component and separately the other, many students did not see the full value of their coursework and would discount large portions of what they learned, reaching for only the parts that they deemed most directly relevant to their career. They were not seeing the benefits of systems thinking to their growth as an engineer. Some students were able to thrive, but the feeling that we were not benefiting all students prompted our change to the Cornerstone model and the continued improvements. Also, as plants grow, they need support and scaffolding of different types. These supports are now derived from the multiple aspects of the first year culture, to be described in more detail below.

Holding the First-Year experience together: The importance of the First-Year faculty team effort

Under the Cornerstone model, the integration of both programming and design were a beneficial mix to aiding student growth. This mix of design and programming could not have been achieved if it were not for the first-year faculty providing constant feedback to each other and forming a tight knit team. This faculty feedback loop is created through bi-weekly meetings with check-in reports from faculty, sharing what worked and what did not. Just as we encourage our students to learn from their failures, it was imperative for our team to learn from one another's failures and successes with the various projects, materials, and innovations that we were introducing to the course. Through this loop, we ensured that the core content of our Cornerstone sections was uniform while still allowing the freedom for faculty to make each course their own. The most important aspects in developing our faculty team culture has been setting aside time and ego for a diverse team of faculty to share insights. This sharing of views allows us to give our course relevance to our students. Some examples include incorporating current events, discussing the ethics of leading edge technologies, and introducing engineering best practices that focus on achieving innovative products.

Scaffolding Students’ Growth: How Physical Space and the Right Supports Can Promote Growth The Culture of a First Year Project

The nature of the kinds of team projects that can be assigned to students in Cornerstone has evolved. For a current list of our project descriptions, please see Appendix A. Cornerstone 
projects can be based on not only the engineering design cycle but also computer programming, data analysis, and microcontrollers and related electronics. Further, the series of projects students complete can build as a sequence over the full 8 credits of coursework such that final projects are significantly bigger, more inclusive to the many aspects of modern engineering design, and more benefitting from repeated practice in team project work by the students. As an example, in a section with a theme of games, the first project had students design and create a lawn game for a person with an identified need. These projects were relatively simple in design and mechanics, and the work focused mostly on the basics of teamwork and project construction as well as understanding the engineering problem as satisfying the needs of a client (who was fictional for this project). The second project asked students to create an original, electronics-enhanced tabletop game. In addition to requiring both physical construction and programming, students worked for a real client. Students had to meet with the client to understand and suit his/her needs and desires; however, the client was a college student and thus not very different from the students. Finally, the third and final project had students creating interactive, electronicsenhanced physical games installed and available for play by the public at the Boston Children's Museum. This final project brought together all aspects of the engineering design cycle as students worked for a real client to design, build, and code durable projects for an end user that has needs and desires significantly different from themselves. This progression is typical to all of the other Cornerstone themes.

\section{The First Year Engineering Learning and Innovation Center (FYELIC)}

A physical makerspace has been created that fosters interaction between first-year students in all sections of Cornerstone, the faculty teaching and supporting Cornerstone, and undergraduate and graduate teaching assistants [16]. The space holds many basic tools, including hand and small power tools, 3D printers, tabletop CNC machines, open computers with all Cornerstone software installed, and meeting spaces. The space is staffed weekdays into the late evening by teaching assistants and, during working hours, professional staff and faculty. All Cornerstone teaching faculty have their offices surrounding this space, increasing the planned and unplanned encounters among Cornerstone students and faculty. This space has become very well utilized, and it is common to hear students from different sections of Cornerstone help each other after overhearing a conversation about a problem that they are experiencing.

\section{Support Staff and "Red Vests"}

Staff for the FYELIC has also grown. In 2016, a technical operations manager was put in place to provide continuous technical expertise on every topic. This person had taught Cornerstone, he was uniquely familiar with the course and students, and is knowledgeable technically as a mechanical engineer. In addition, the manager had previously advised a FIRST Robotics team and brought considerable dedicated technical strength and desire to work with students on every Cornerstone skill and project. With all of the students looking for help in the center, a new problem emerged in that this technical operations manager could not do all of the tasks needed to efficiently run the FYELIC. In Fall 2017, an Academic Assistant was hired to organize, manage, schedule, and keep the center running in support of the students. This combination of strengths has provided huge improvements. With clear areas for working, machines that are kept running 
efficiently, supplies stocked, TAs scheduled when needed, and more, students are utilizing the space much more than ever before. The space supports students when and how they need it. Previously, it took weeks into the semester before the center got busy; now students are there from the first day of the semester. Student tracking has shown a steady rise in FYELIC usage, and the overflow of students spilling out of the FYELIC into the hallways at the end of the semester as students madly try to finish their projects has become a topic of discussion around the college. We rely on the University's Facilities Department to bring in additional tables to safely expand the center into the hallways during these times.

There is a great deal of use of the engineering design process to solve problems every week. One example is the Red Vests. Previously, when students arrived at the FYELIC to get help, they were often intimidated and unsure of how to approach anyone for help - or even how to identify who was available to help. Seeing that a name tag was not enough to help identify a TA, red safety vests were purchased. After many options were discussed by the team, this small change led to a large benefit. Every TA now wears a red vest to identify him/herself, and students can now immediately and easily see who is available for questions and help.

\section{Teaching Assistants}

The Cornerstone faculty have begun asking select students from previous years to continue working with the Cornerstone program. A number of work roles for the returning students are available. Some students work as teaching assistants (TAs) in the FYELIC. Other students work as teaching assistants tied to specific sections of Cornerstone, where they generally assist in grading and other day-to-day details of running a section of the course. Finally, some returning students are hired to work as mentors to teams of current students or act as clients for their projects. In all of these roles, returning students help maintain an institutional knowledge about particular techniques and help pass on ideas about what has succeeded or failed in past projects.

With the co-reinforcing supports of returning students, increased personal interaction among students and faculty, and the ability to assign and expect completion of more complex and, ultimately, interesting projects, a true shift has been occurring in the development of a first year engineering culture. The shift to a first year culture is analogous to the culture that often develops in architecture or art programs that have intense studio programs in the first year.

\section{Creating a feedback loop that enriches the program}

\section{Student Feedback Teams \& End-of-Semester Student Perception Surveys}

Student feedback teams were utilized during the second year of the Cornerstone model in order to foster real-time response from students on all aspects of the course. Before the semester, the faculty team attended a training session on their use from our University's Teaching and Learning Center. Many, but not all, faculty continue to use student feedback teams.

Each instructor working with these teams yielded different results, as might be expected, but the process identified a number of more effective teaching strategies that the team adopted. One major revision was to "chunk" the material more. In our enthusiasm for integrating all of our 
skills and concepts into projects, instructors tended to teach several topics concurrently. For example, a section might discuss AutoCAD on Monday, design on Wednesday, and $\mathrm{C}++$ on Thursday. Following the feedback from student feedback teams, instructors have now readjusted schedules to increasingly use just-in-time, project-motivated "chunks." For example, the course might start $\mathrm{C}++$ over a few weeks as the students began programming with Arduino based kits. Later, when it is approaching a time when projects might need laser cut parts, the course focuses on using AutoCAD. This may seem an obvious change, but coordinating the projects to coincide with the semester schedule to achieve this just-in-time learning can be difficult to accomplish in practice, especially since we desire all of the skills to be needed for the final project. This change made a big difference in students keeping up with the work, understanding why they were learning it, and avoiding what they called "topic whiplash".

In the end-of-the semester surveys, a common complaint among Cornerstone students was that the order of presentation of the various content areas felt somewhat scattered or disorganized. This is the same feedback received from the student feedback teams described in the preceding paragraph. This feedback is likely due to the faculty desire to maximally instill the integrated nature of the Cornerstone approach via the class's semester schedule. There is a freedom for the faculty in being able to schedule the different content areas throughout the semester as desired, as opposed to the previous approach which segregated the content areas into separate classes. These new schedules are still much more integrated than the pre-Cornerstone approach, and allow for a much richer approach to the foundations of engineering.

A survey of student perceptions of the courses is shown in Table 1. This survey focused on the Cornerstone Course and was separate from the University-administered, end-of-semester student evaluations. At the time, both the Cornerstone and non-Cornerstone courses were still being taught - i.e., not all first year students were in Cornerstone as we continued to pilot the approach increasing capacity incrementally. Having students randomly assigned to the Cornerstone and non-Cornerstone course versions provided a natural experiment, allowing us to compare many of the attributes of the courses. Table 1 shows Cornerstone provides an improved experience in a number of categories, significantly so in perceptions of the projects, the introduction to engineering concepts, and value of hands-on experience. Fortunately, all of our courses are providing a positive improvement in perspective on engineering, and the confidence in becoming an engineer is almost equal across the course types.

Figure 3 shows the course evaluation data in aggregate for the first-year courses, all sections and all instructors. The trend justifies the changes to cornerstone and our focus on the next iteration. Overall average effectiveness has varied slightly between 4.2 and 4.4 over the years of implementing the two course model up to 2014 (on a 1 - 5 point scale). The figure shows a slight decline trend in 2014, coinciding with the start of the cornerstone pilot and then an increase in the number of sections of the course and new faculty teaching them. As with any major change there is a learning curve, and we now see starting in 2016 a positive upward trend as cornerstone matures and we continue refining it. With continued effort, we hope to remain on this trajectory! We do note that new faculty hires in 2015, 2016, and 2017 may have an effect on those years. 
Table 1. Relevant average responses from the University-administered student perceptions and feedback survey.

\begin{tabular}{|c|c|c|c|c|c|c|}
\hline & \multicolumn{6}{|c|}{ Spring 2016} \\
\hline & \multicolumn{2}{|c|}{ All Data } & \multicolumn{2}{|c|}{ Design/Programming } & \multicolumn{2}{|c|}{ Cornerstone } \\
\hline & \multicolumn{2}{|c|}{$\mathrm{N}=440$} & \multicolumn{2}{|c|}{$\begin{array}{c}\text { Original Two Course } \\
\text { Series }\end{array}$} & \multirow[b]{2}{*}{ Average } & \multirow[b]{2}{*}{ STD } \\
\hline & Average & STD & Average & STD & & \\
\hline $\begin{array}{l}\text { How did your perspective on } \\
\text { engineering change after taking this } \\
\text { course? ( } 1 \text { to } 4 \text { = more positive) }\end{array}$ & 3.798 & 0.717 & 3.643 & 0.796 & 3.906 & 0.636 \\
\hline $\begin{array}{l}\text { Based on your experiences so far, do } \\
\text { you think you have the ability to } \\
\text { become an engineer? ( } 1 \text { to } 5 \text { = agree } \\
\text { strongly) }\end{array}$ & 4.3 & 0.815 & 4.270 & 0.861 & 4.321 & 0.783 \\
\hline $\begin{array}{l}\text { The courses provided a (1=fair to } \\
5=\text { excellent) introduction to } \\
\text { engineering concepts. }\end{array}$ & 3.84 & 1.013 & 3.562 & 0.993 & 4.034 & 0.982 \\
\hline $\begin{array}{l}\text { The projects in my courses provided } \\
\text { valuable hands-on engineering } \\
\text { experience.(agree } 1-5 \text { ) }\end{array}$ & 4.138 & 0.825 & 3.914 & 0.836 & 4.294 & 0.781 \\
\hline
\end{tabular}

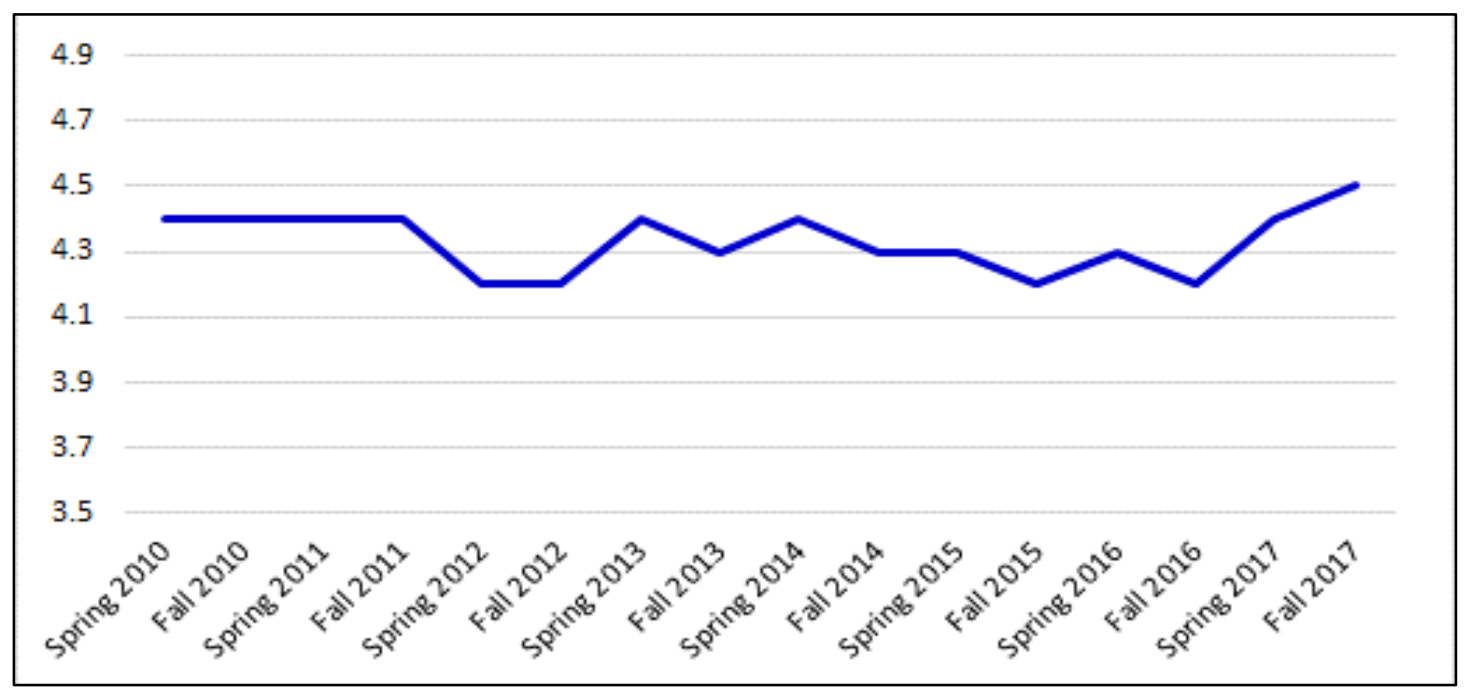

Figure 3. Average first year faculty "Instructor Teaching Effectiveness" as reported by students in the University-administered end-of-semester perception survey. Y-axis rating is on a 5-point scale. 
Figure 4 presents the results of faculty who have been teaching with our first year program for three years or more and have been involved in cornerstone planning and teaching. The effect of continual course improvement is exemplified in several cases presented here. Looking at individual instructor scores from the University-administered student perception survey data, we see the story of how capital improvements and the feedback has aided in teaching effectiveness score improvement. For instructor A, we see a large jump in teaching score with the completion of the learning center between arrows 1 and 2. Looking at the specific case of Instructor B, we see that with any first time teaching a course there is a drop in the students' scoring of teacher effectiveness. The drop in effectiveness score is compared to scores for teaching the original model of design and programming in separate courses (arrow 2). Instructor B then taught full cornerstone the following year (arrow 3) with several changes aiding the student's learning, including the addition of SMTs and student mentors. These interventions, along with the experience that comes with running a course over again translated into improved scores. The following semester (arrow 4) the full cornerstone was offered for the first time in the spring, and the increases in iteration can be seen in instructor B's scores. Much of this can be attributed to individual experience, incorporation of comments from students, and sharing of materials and experiences among all first-year instructors. Finally, the greatest improvement that helped close the gaps between many of our instructors' scores was the expansion of our learning center. The space that was direly needed to enable our students' success outside the classroom translated into supports that enabled students to grow and appreciate their learning inside the classroom. This can be seen in the scores from Instructors B and C at arrow 5.

Overall, the changes instituted over the past few years have enabled all of our instructors to improve their teaching effectiveness scores in a way that closed the gap in teaching scores for our instructors (arrow 5.) We attribute this to the creation of the first year culture. As faculty, we are providing a unified approach to topics inside the classroom informed through our feedback loops. Outside the classroom, we have an experienced support team of staff and upperclass students in the FYELIC that reinforces our teaching approach and helps scaffold our students' learning. 

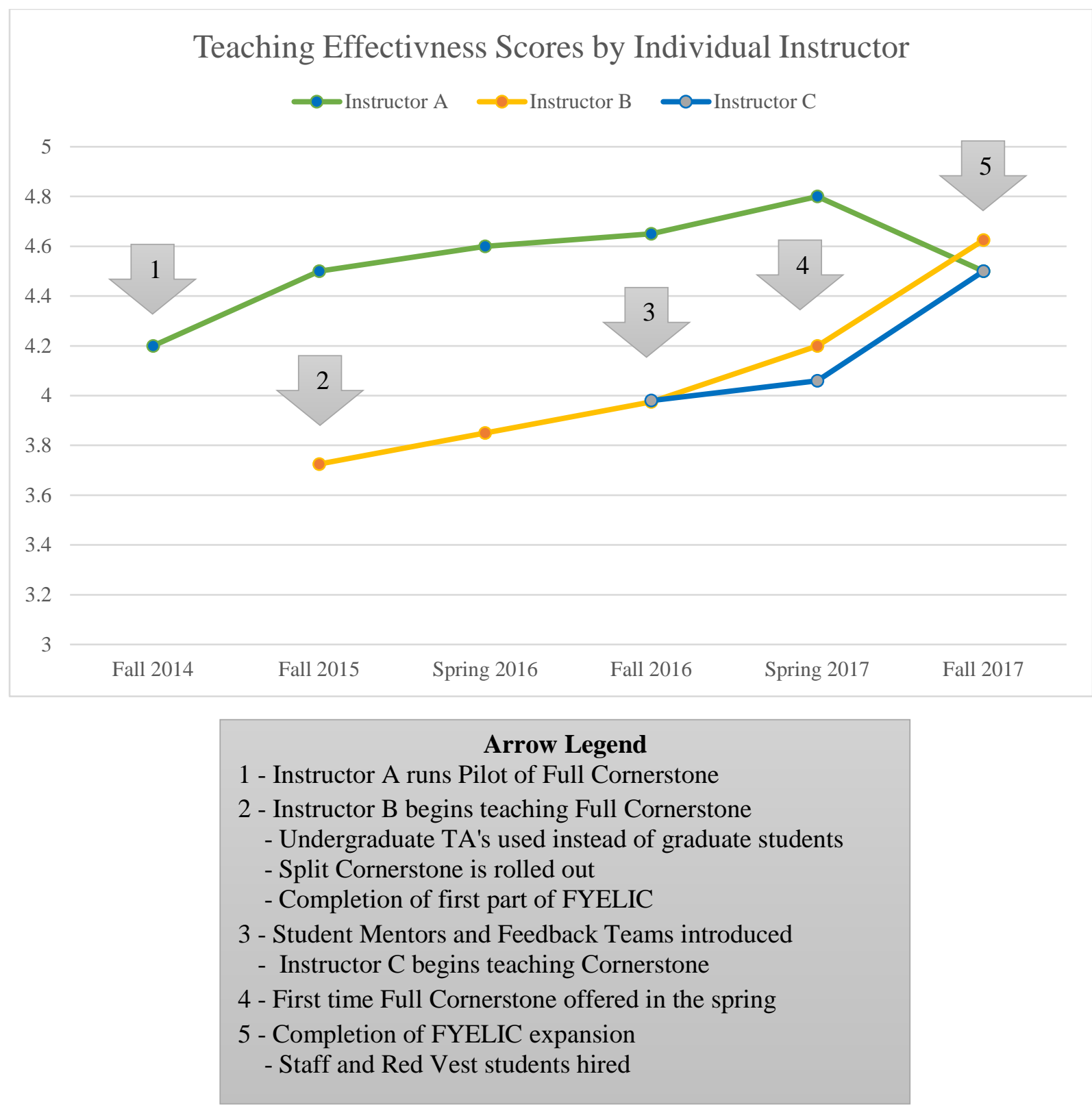

Figure 4. Individual first year faculty scores for Teaching Effectiveness, on a 5-point scale (1 Never Effective, 2 Rarely Effective, 3 Sometimes Effective, 4 Usually Effective, 5 Almost Always Effective)

\section{Evidence of Culture Shift from the Survey}

Using data from the spring 2016 surveys previously mentioned, the free response questions were coded for any mention of aspects of a shift in the first-year culture, comparing the students in Cornerstone and non-Cornerstone sections. The open-ended questions asked:

- What helped your learning in this course?

- What suggestions for the course do you have to improve engagement or learning?

- What suggestions do you have to improve the course? 
Responses were evaluated using a combination of conventional, directed, and summative multipass content analysis to categorize responses by patterns and categories using multiple independent coders [17]. We looked for mentions of culture - i.e., people and place - that was outside of a class's expected student-professor interaction and classroom location. Culture was evaluated in three dimensions. The first dimension was peer-to-peer collaboration, defined as mention of teams, teamwork, partners, peers, classmates, teammates, or friends. The second dimension was the FYELIC space. The third dimension was mentorship, defined as mention of TAs, FYELIC staff, tutors, or mentors. There was no direct mention of any of the culture terms in the questions, so all responses were unprompted. The responses were coded as positive or negative for each and the results are shown in Figure 5.

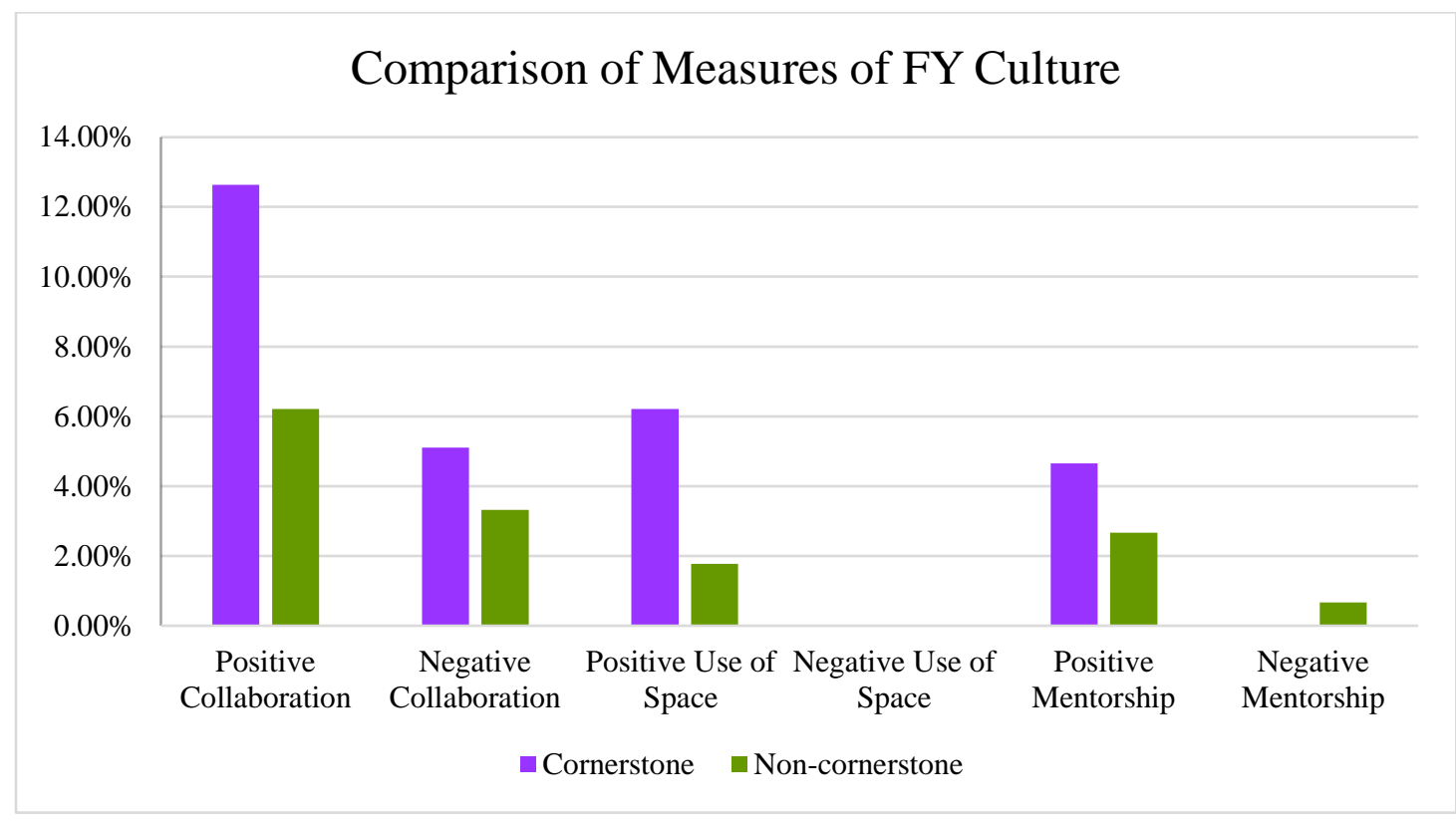

Figure 5. Comparison Measures of First-Year Culture in Cornerstone versus Traditional Non-Cornerstone course sequences.

In all three dimensions of culture, there were clearly more comments from the students in Cornerstone sections. The $N$ for each set is 260 for Cornerstone and 180 for Non-cornerstone which is a significant representation from both course types. Overall, cornerstone has more positive aspects of each dimension and more total even after only the first year of implementation. We see from the figure that students coded to "positive collaboration" $12.6 \%$ for cornerstone as compared to only $6.2 \%$ for non-cornerstone, "positive use of space" $6.2 \%$ for cornerstone as compared to only $1.7 \%$ for non-cornerstone, and "positive mentorship" $4.6 \%$ for cornerstone as compared to $2.2 \%$ for non-cornerstone. In addition, we now have since this survey further evidence that an increase in positive culture that has been created by Cornerstone. There is a significantly increased number of students in the FYELIC, an increased number of students asking to be TAs (often before they have even finished the course) and increased requests to work in the FYELIC after experiencing the positive outcomes firsthand. 


\section{$\underline{\text { Conclusions }}$}

Now in its fourth year of evolution, the future curriculum for first-year engineering students at Northeastern University continues to look bright with opportunities for our students to experience design and innovation firsthand. With constant feedback from our students and collaboration among a close-knit faculty team, we have developed two approaches to the Cornerstone model that successfully prepare various cohorts within our student population for post-first-year engineering curricula. Both the Full Cornerstone (integrated 8-credit course in one semester) and Split Cornerstone (integrated 4-credit course in two semesters) models have been shown to create a positive culture within the student body that the previous two course sequence lacked. The students are exposed to real world engineering challenges, and the Full Cornerstone in the Fall semester allows our most competitive students the opportunity to pursue classes in their intended major earlier (spring of first-year) giving them an advantage in the pursuit of research and job opportunities after the first-year. In addition to these direct instructional benefits for the students, we have seen positive outcomes from faculty performance. Overall teaching effectiveness has increase as our faculty teach new concepts in programming, design, microelectronic control and graphical communication in relation to needing such skills in order to solve a problem related to their Cornerstone theme. We see firsthand the positive outcomes of this approach in both student and faculty satisfaction and will continue to refine our courses based on feedback and research.

\section{$\underline{\text { References }}$}

[1] First Year Engineering Learning \& Innovation Center, Northeastern University, 2018.

[2] National Academy of Engineering. Educating the engineer of 2020: Adapting engineering education to the new century. Washington, D.C.: National Academies Press, 2005.

[3] S. Ambrose and C. Amon, "Systematic Design of a First-Year Mechanical Engineering Course at Carnegie Mellon University", Journal of Engineering Education, vol. 86, no. 2, pp. 173-181, 1997.

[4] C. Dym, S. Sheppard and J. Wesner, "A Report on Mudd Design Workshop II: “Designing Design Education for the 21stCentury”", Journal of Engineering Education, vol. 90, no. 3, pp. 291-294, 2001.

[5] C. Dym, A. Agogino, O Eris, D. Frey and L. Leifer, “Engineering Design Thinking, Teaching, and Learning”, Journal of Engineering Education, vol. 94, no. 1, pp. 103-120, 2005.

[6] C. Dym, M. Gilkeson and J. Phillips, "Engineering Design at Harvey Mudd College: Innovation Institutionalized, Lessons Learned", Journal of Mechanical Design, vol. 134, no. 8, p. 080202, 2012. 
[7] J. Gasiewski, M. Eagan, G. Garcia, S. Hurtado and M. Chang, "From Gatekeeping to Engagement: A Multicontextual, Mixed Method Study of Student Academic Engagement in Introductory STEM Courses", Research in Higher Education, vol. 53, no. 2, pp. 229261, 2011.

[8] S. Ambrose. How learning works: Seven research-based principles for smart teaching. $1^{\text {st }}$ edition. San Francisco, CA: Jossey-Bass, 2010.

[9] E. Nuhfer, "A handbook for student management teams", 2008 (original work published 1991). [Online]. Available: http://profcamp.tripod.com/New_PM_Intro_SMT.pdf.

[10] J. Troisi, "Making the Grade and Staying Engaged", Teaching of Psychology, vol. 41, no. 2, pp. 99-103, 2014.

[11] J. Troisi, "Student Management Teams Increase College Students’ Feelings of Autonomy in the Classroom", College Teaching, vol. 63, no. 2, pp. 83-89, 2015.

[12] J. Cullen and L. Johnston, "Using Quality Circles in the Classroom to Improve Student Learning and Satisfaction”, Journal of Nursing Education, vol. 38, no. 8, pp. 368-370, 1999.

[13] American Society for Engineering Education, Advancing the Maker Movement: Making and Makerspaces at Engineering and Engineering Technology Schools and Departments and the Non-Engineering Academic Maker Community. Washington, D.C., 2017.

[14] M. Galaleldin and H. Anis, Impact of Makerspaces on Cultivating Students' Communities of Practice, in Proceedings of the American Society for Engineering Education National Conference, New Orleans, LA, June 24-28, 2017, Paper ID \#20041.

[15] V. Bill and A-L Fayard, Building an Entrepreneurial and Innovative Culture in a University Makerspace in Proceedings of the American Society for Engineering Education National Conference, New Orleans, LA, June 24-28, 2017, Paper ID \#19601.

[16] J.O. Love, S.F. Freeman, S.F., B.K. Jaeger-Helton and R. Whalen, No lab? No shop? No problem: Intentional design of a First Year Engineering Learning Center with enlightening outcomes in Proceedings of the American Society for Engineering Education National Conference, Seattle, WA, June 14-17, 2015, Paper ID \#13479.

[17] H. Hsieh and S. Shannon, "Three Approaches to Qualitative Content Analysis", Qualitative Health Research, vol. 15, no. 9, pp. 1277-1288, 2005. 


\section{Appendix A}

In both the Full and Split versions, the cornerstone courses were carefully designed to set up our first-year students to be successful in their 2nd year of engineering, regardless of major.

Therefore, the courses include specific themes centered on a number of design-and-build projects with the core outcomes of:

- Applying the design process.

- Design and construct to design specifications.

- Engineer a solution to a real problem.

- Graphical Communication and 3D printing.

- Professional skills: oral and written skill practice, presenting design solutions.

- Computational programming skills - $\mathrm{C}++$, Matlab, using programmable microcontrollers.

- Focus on sensing and input/output.

- Numerical analysis and calibration of sensors.

In order to free up class time for project work, many of the course elements were flipped. The flipped classroom model allows more time for hands on activities, team project work, and inclass feedback from the professor. Additional advantages to the cornerstone model are that the students are able to design projects with a systems approach, and to simulate real projects with complex solutions. Core course concepts such as applications of programming, graphics and the design process are integrated naturally and are not forced. This gives immediate confirmation that the topic is relevant as they have to apply it in order to solve their problem. Finally, students can explore and research engineering principles due to their interest and the project requirements which leads to further fulfillment of effort.

\section{Cornerstone - Structure and Content}

For each of the different themes, milestones and projects support the course objectives with appropriate, real world application-inspired end goals. These are done in a similar order across the sections, but not all sections use the same course structure and approach. All split cornerstone sections teach the same elements of design, programming, ethics and graphical communication regardless of theme each semester. This coordination allows students to move freely between split cornerstone I and II sections in the Fall and Spring to accommodate a schedule change without loss of content. The focus of the following discussion is to provide a brief overview of the project activities and to provide some detail on how to get to the final outcomes and projects.

\section{$\underline{\text { Robotics }}$}

Currently the robotics theme is taught in the split cornerstone version. The design teams are formed at the beginning of the Fall semester (2nd week). The teams were changed in the Spring and both semesters had teams of three to five members based on the class size. In the first semester students developed an autonomous battle bot to be used in a Sumo Wrestling competition and competed against fellow classmate robots. In the second semester students were given a list of suggested problems or the choice to develop their own needs assessment where 
robotics would be a part of the solution. Examples of the prototypes developed in the second semester were an automatic pill dispenser using facial recognition, robotic exploration of a disaster area or hazardous area, robotics used in manufacturing area application, prosthetic hand design, automatic cat teaser, robotic beverage delivery system, radiation detector robot and a home security scout robot.

\section{Efficient Energy (Production/Transfer) System}

This section was a full cornerstone which is an 8 credit 1 semester course. The teams were formed at the beginning of the semester (2nd week). Each team had four or five members based on the class size. Few team activities were given to build team interaction, including a case study project on energy system. The objective of the case study activity was for students to explore and get the basic knowledge on existing energy production and transfer system via literatures and/or field trip. The cornerstone final team project has a similar theme as the case study for each team. The students developed a working prototype along with methods to test its efficiency in the following project topics: Energy Production Efficiency with Stirling Engines, Rooftop Wind Turbines, Tidal Energy, Regenerative Braking Elevator, Airborne Wind Generation, Wind Fan Design and Analysis and a solar powered winch system.

\section{Games I - Virtual Reality}

This section of the cornerstone course is offered in the split cornerstone version. The project in the Fall semester was to create a mini-golf hole based on a science or math theme (i.e. friction, gravity, Pythagorean's Theorem). The teams were formed during the third week of the fall semester. Each team had four members in the fall and the teams were changed in the Spring and had three or four members based on the class size. There were team building activities in the first semester along with use of a web-based team rating system to help facilitate team functioning. The Spring project was to create an input device for use with video games and virtual reality. Teams could choose between three different types of input devices: One handed design: a fully functioning input device that was usable with just one hand, Fitness/health: an input device that uses health or fitness sensing as part of its operation or Education: an input device that uses STEM education as part of its design.

\section{Games II - Game Design}

The games theme is taught in the split cornerstone version. Three projects were required, two in the fall and one in the spring. Design teams of four students changed for each project, scrambling them so that no one worked with the same student twice. In the first project, students developed and built a lawn game (such as horseshoes or corn hole) that is fully playable by someone with an identified physical or cognitive need. Each team chose the basis of the player's disability, a style of game that would normally be difficult for that player, and then a means of enabling that player's full participation. For the second project, teams interacted with a real person, an upperclass student, who acted as a client. Teams designed and built an electronics-enhanced tabletop game for their client. An emphasis of this project was designing to meet the needs of the client, and so a small grade bonus was received by the team that created the client's favorite game. In the spring semester, teams build a physically interactive, electronic game for children. The 
games were installed for a day at the Boston Children's Museum for visitors to play and enjoy. In addition, the eight teams from each section worked together to give their set of games an overall theme and structure, such as a riddle that is solved by collecting clues from each game.

\section{Sustainability I - Smart House}

The sustainability theme is taught as a full cornerstone. There are one semester long design project and three minor design projects given throughout the semester. These project were done in groups of 4 , which were put together the second week of class. The object of the semester long design project was to design a sustainable and independent home in Greater Boston by completely eliminating the use of energy and water from outside sources (grid) and utilize local and/or sustainably harvested/produced materials.

The three minor design projects were used to learn and build on the idea of sustainability and sustainable buildings. These projects were hands-on where the students designed, tested, and analyzed data from their designs and were able to use that data to redesign and improve upon their original designs. The projects were to: design and build a solar water heater that provided the warmest water for the longest time compared to others groups in the class, to build a thermostat using Arduino microcontroller boards and to design a passive solar box with the goal to maintain the temperature inside the box between $65^{\circ} \mathrm{F}$ and $85^{\circ} \mathrm{F}$ for the longest time possible compared to other groups in the class.

\section{$\underline{\text { Sustainability II - Resiliency }}$}

The sustainability and resiliency themes are currently taught in the full cornerstone version. Design teams (typically 4 students) are formed within the first week and kept throughout the semester. The first task is the minor design project: pasta bridges. Groups are asked to design a bridge based on maximizing their strength to weight ratio to simulate the importance of making smart decisions in material selection. The bridges are then tested using the ADMET machine and a 3-point bending apparatus to give the students a displacement vs. load profile where they then analyzed the data in Matlab to calculate the toughness of each bridge. Following the bridge testing is the major design project in which students are asked to create a museum exhibit that teaches a concept of sustainability or resiliency to a child. Students are asked early on to visit the local Science Museum to get an idea of what a fun museum exhibit entails and to facilitate design ideas. Currently, this cornerstone theme partners with local community schools and designs the exhibits to fit the interests of real clients. At the end of the semester, our community client is invited to come to our "Pop-up Museum of Sustainability and Resiliency” where our students can interact with our young clients and reflect on how their designs were received. Popular examples of museum exhibits from the most recent prototypes have included a Disney's Moana themed exhibit that taught about smart housing design in flood zones, a Star Wars themed exhibit that educated on the importance of energy savings, and a Plants vs. Zombies themed exhibit that taught about the different types of farming practices that can be used in an urban setting. 


\section{Security}

This section of the cornerstone course is offered in the split cornerstone version. Project teams of, generally, four students were formed at the beginning of each semester, with the teams scrambled between the Fall and Spring semesters. The following projects supported the overall course learning objectives in the Fall Semester: The Launch Box: The focus of this first project was a device/system was to build a small device that enabled a single person to launch a small payload into the air with as little notice as possible -to collect data in a crowd. Groups could choose between a few different (simulated) payloads, with different height and mass requirements. That's a Fugazi - Student teams had to design and construct an Arduino-based device/system that enabled a border control officer too quickly and easily test whether received goods are valid or counterfeit. The device had to use at least two sensors chosen by the students to detect the validity of the good being tested. For example, a counterfeit item might have had a different weight and a weaker magnet than the valid samples. In the second semester each team had to design and construct a robot that autonomously found and alerted to the presence of a simulated threat. The only interaction a student could have with their robot was pushing a button to have it begin moving. The goal was for the robots to find as quickly as possible a simulated chemical weapon in the form of an open container of isopropanol. 